\title{
Textbooks and the Dilemmas of Teaching Political Theory
}

\author{
Matthew J. Moore, California Polytechnic State University
}

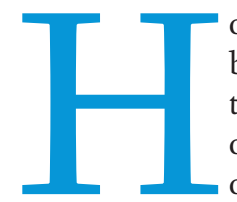
ow should one choose a political theory textbook? Why would one want a political theory textbook? In the 1970s, nearly half (43.2\%) of political theory courses were taught using only textbooks, and an additional $29 \%$ used textbooks in combination with primary texts (Hajjar and Brzezinski 1978, 300). But in 2008 political theorists reported that they were most likely to use only primary texts, and the average theorist reported that only $11 \%$ of the texts they assigned were secondary texts like textbooks (Moore 2011,107). That suggests a sea change away from the use of textbooks and in favor of using primary texts. Given the easy availability of free primary texts online, that trend seems likely to remain strong.

Yet there are a number of excellent textbooks available, and textbooks have much to recommend them, either in combination with primary texts or standing alone. To see textbooks' merits, it might help to think for a moment about the experience we want undergraduate students to have in taking an introductory course in political theory. Ideally, I would want a student completing a political theory course to understand the broad range of concerns of political theory (authority, justice, identity, and so on), and also to have looked deeply into at least one such issue. I would want them to be familiar with the names and basic ideas of major figures in the history of political thought, while also understanding that there are many other thinkers, traditions, and concerns that the canon leaves out or intentionally downplays. I would want them to appreciate that there are many different, defensible ways to read texts and analyze arguments. I would want them to have begun to become aware of their own assumptions, cultural embeddedness, prejudices, and presumptions, and to have some tools and habits for coping with those aspects of their worldview. I would want them to appreciate the motivations that drive people to write and study political theory. I would want them to develop a sympathetic understanding of why arguments that seem bizarre today were (and perhaps still are) compelling and plausible, alongside a beginning understanding of the importance of reading a text in its historical context. I would want them to have a beginning understanding of how various debates have evolved over time, and to appreciate that the history of political thought contains both continuities and dramatic ruptures. Finally, I would want them to have improved a set of intellectual skills, namely the abilities to read complex texts, to subject arguments to criticism, to approach challenging ideas and arguments charitably, to write clear expository essays, and to be able to view their own ideas and commitments as simultaneously deserving expression and requiring critical reflection.

The problem is that there are only so many class hours in the term, so many pages of reading that it is reasonable to assign, so many essays that one can grade (or conscionably assign to TAs to grade). What we actually accomplish in our classes is inevitably a compromise, the result of choices we make about a handful of trade-offs:

- Breadth vs. Depth - Do we have our students learn a little bit about each of a large number of thinkers and issues, or a lot about a small number?

- Text vs. Context - Do we emphasize texts and their arguments, or their contexts and roles in long-term debates and developments?

- Debate vs. Meta-debate - Do we emphasize the debates within political theory texts, or the debates about political theory texts?

- Macro vs. Micro - Do we provide a bird's eye view and leave it to students to apply that to individual thinkers, texts, and arguments, or do we provide detailed readings of a handful of texts and leave it to students to generalize about the field more broadly?

- Raw vs. Cooked - Do we leave students to figure out what texts say/mean so that they learn important reading and thinking skills, or do we tell students what the texts say so we can get right into assessing and comparing the arguments?

In each of these dilemmas, primary texts embody one virtue, while secondary texts embody the opposing virtue. There is clearly a defensible case for using either or both. So what textbooks are currently available, and are they any good?

\section{METHODOLOGY}

To answer those questions, I decided to look at a handful of the most popular textbooks currently available for teaching an introductory course in political theory (see table 1). I excluded anthologies of primary texts as well as textbooks that focus on a limited time period (for example, ancient and medieval), subject (for example, feminist political thought), or region (for example, Asian political thought). I included only textbooks that are in print and easily available, defined operationally as being for sale new through Amazon.com. ${ }^{1}$ I searched for books, using a wide variety of search terms (political theory, philosophy, thought, thinkers, ideas, and so on), through Amazon, Google, and on numerous publishers' websites. In the end, I identified 45 texts that met the criteria. 
Table 1

Books Reviewed in this Article

Political Ideologies (11th Edition). By Leon P. Baradat. London and New York: Routledge, 2012. 368 p. \$95.00 paper.

Political Philosophy. By Steven B. Smith. New Haven and London: Yale University Press, 2012. 282 p. \$25.00 paper.

An Introduction to Political Philosophy (Revised Edition). By Jonathan Wolff. Oxford; New York: Oxford University Press, 2006. 215 p. \$34.99 paper.

Political Philosophy: A Very Short Introduction. By David Miller. Oxford; New York: Oxford University Press, 2003. 147 p. \$11.95 paper.

Introduction to Political Theory (3rd Edition). By John Hoffman and Paul Graham. London and New York: Routledge, 2015.524 p. \$54.95 paper.

History of Political Theory, An Introduction; Volume I: Ancient and Medieval (2nd Edition). By George Klosko. Oxford; New York: Oxford University Press, 2012. 373 p. \$44.95 paper.

History of Political Theory, An Introduction; Volume II: Modern (2nd Edition). By George Klosko. Oxford; New York: Oxford University Press, 2013. 570 p. \$44.95 paper.

Political Ideologies and the Democratic Ideal (9th Edition). By Terence Ball, Richard Dagger, and Daniel I. O'Neill. London and New York: Routledge, 2013. 368 p. \$94.95 paper.

To rank them in terms of popularity, I used their relative Amazon sales rankings. ${ }^{2}$ In consultation with the editors of $P S$, I chose the top seven texts to review.

I discuss each of the books individually below; here I have a few things to say about them collectively. First, all of the books under review are scholarly, well written, and accurate (or at least defensible), though I have a few specific criticisms and complaints below. Second, the books group naturally into three types, which also appear to apply to the other textbooks I identified:

(1) True Textbooks (Baradat; Hoffman and Graham; Ball, Dagger, and O'Neill)-These are books that our colleagues in other subfields of political science would recognize as textbooks: they are amply illustrated and use engaging typography; they have sidebars and pull outs discussing terminology, important individuals, and so on; they have glossaries; and they come with supplementary materials (like websites, question banks, PowerPoint slides, and so on).

(2) Monographs-as-Textbooks (Smith; Klosko)-Although these books are intended to be used as textbooks, they are closer in style to a scholarly monograph than to a typical undergraduate textbook. Thus they are sparsely illustrated (Smith) or unillustrated (Klosko); they use the typography of monographs, and their texts flow in one continuous stream without visual interruptions or diversions; they do not include glossaries, and do not come with supplementary materials (Smith being a partial exception; see below).

(3) Supplementary Monographs (Wolff; Miller)-These two books are clearly intended to be used as supplements to other materials, probably primary texts. Thus they are written and typeset like monographs, are brief (Wolff is 215 pages, Miller 147), and both are focused on explaining what political philosophy is to a general audience. Neither contains a glossary or comes with supplementary materials.

These different approaches to the form and purpose of a political theory textbook suggest that textbooks are used in different ways, which indicate different strategies for balancing the opposing goals of the trade-offs discussed above.
Hoffman and Graham, at roughly 500 pages and coming with extensive supplementary materials, is clearly meant to be either the sole book for a course or at least the book from which the vast majority of readings will be assigned. The same is roughly true of Ball, Dagger, and O'Neill, though that text has an optional companion volume of primary texts, and at 350 pages the textbook alone would not be enough reading for a whole term. Baradat is also roughly $35^{\circ}$ pages and comes with relatively few supplementary materials, so it would also need to be supplemented with other readings, though it, too, is clearly intended to be a course's main text.

Klosko is also clearly intended to be the primary or even only text for a course, and at a combined total of nearly 1,00o pages the two volumes provide plenty of reading for students. 3 Smith is a bit of an outlier, since it is based on Prof. Smith's lectures from his introductory political theory course at Yale, and is issued as part of Yale's Open Courses project. I think its main purpose in life is to be the textbook for someone who is independently completing the work for Prof. Smith's course by watching his lectures online and reading the textbook alongside. But it would certainly work as a textbook for a more traditional course, supplemented with primary texts.

Finally, Wolff and Miller are clearly not meant to be the primary texts for an introductory course, but rather are brief, clear introductions to the broad concerns of political philosophy for a general reader. Like Smith, they would be good books for a non-student who was interested in the topic, but would also be very good as texts to provide analytical structure to a course whose main readings were primary texts.

Because the books under review group themselves in this way, in a sense they are not competing all against each other, but rather each against the other members of its category. Thus my comments on the individual texts are grouped by category, so that similar books may easily be compared.

\section{TRUE TEXTBOOKS}

\section{Baradat, Political Ideologies (11th edition)}

The title of this text reveals yet another way to group the books under review. Baradat and Ball et al. focus on ideologies, in explicit contrast to political theory or philosophy. Although they 
differ somewhat in their definitions and assessments of ideology (more on that below), the two texts roughly agree that political theories / philosophies are sophisticated, profound, elite inquiries into truth, while ideologies are relatively simple, action-oriented attempts to mobilize the masses. In contrast, Klosko, Smith, Miller, and Wolff are examining political theory or philosophy, and do not distinguish it from ideology. (Indeed, the term ideology doesn't appear in any of their indexes except that of Klosko, where it refers to his discussion of Marx.) Hoffman and Graham try to have it both ways, starting off with a discussion of classical political ideas, then discussing classical ideologies before turning to contemporary ideologies and contemporary ideas. The texts that focus on ideologies identify ideological thinking as a modern phenomenon, leads to an emphasis on relatively recent political ideas, with the result that the earliest thinker to get substantial discussion is Locke. On the other hand, the book is very up to date, and has extensive discussions of Islamism, contemporary Chinese communo-capitalism, and other present-day movements.

\section{Ball, Dagger and O'Neill, Political Ideologies and the Democratic Ideal (9th edition)}

The clearest contrast with Baradat is Ball et al., who cover much of the same ground with a similar analytical approach, but offer a much more robust and well integrated set of explanatory categories. First, they succeed in providing a concise definition of ideology: "an ideology is a fairly coherent and comprehensive set of ideas that explains and evaluates social conditions,

\section{The texts that focus on ideologies identify ideological thinking as a modern phenomenon, and thus focus most heavily on the political ideas of the past three or four centuries up to the present.}

and thus focus most heavily on the political ideas of the past three or four centuries up to the present.

Although it was far and away the best seller among the books under review, and has gone through an impressive 11 volumes, I found Baradat the least satisfying of the true textbooks. The text is organized into two preliminary chapters laying out an intellectual framework and 10 subsequent chapters examining particular ideologies. The discussions of the particular ideologies are generally fine, but I found the intellectual structure of the text much harder to understand. The first chapter is devoted to a nuanced and thoughtful discussion of ideology, but frustratingly it never results in a clear, brief definition. More puzzlingly, the second chapter lays out a framework for categorizing political ideas based on their attitude toward the status quo--thus radicals want to change it in a progressive direction (toward some new social system), conservatives support it, and reactionaries want to change it by regressing back to some prior order. The typology is a bit pat, but on balance is seems like a helpful schema for students to start with. Yet the subsequent chapters don't seem to draw on it very much. For example, two chapters are devoted to liberalism as an ideology, but it's not obvious that one could be a radical liberal (or a reactionary liberal, for that matter), and the later chapters barely mention the framework of political attitudes at all.

Because the text is focused on ideologies, the discussions of individual thinkers and texts are generally brief and are illustrations of broader points rather than deep explanations of the particulars (with the exceptions of Marxism and the varieties of fascism, which are all strongly identified with single thinkers). In general the characterizations of thinkers are fair and accurate (with the notable exception of the discussion of Nietzsche), but the effort to make categories clear and distinctions sharp leads to some oversimplification and smoothing of rough edges. The focus on ideology, as discussed above, helps people understand their place in society, and provides a program for social and political action" (Ball, Dagger, and O’Neill 2013, 5). This definition gives rise to a clear evaluative framework, which is central to the rest of the book: "An ideology, more precisely, performs four functions for people who hold it: the (1) explanatory, (2) evaluative, (3) orientative, and (4) programmatic functions" (Ball, Dagger, and O'Neill 2013, 5). Each subsequent chapter examines an ideology or putative ideology and explicitly assesses it in terms of this framework.

As with Baradat, most of their discussions of particular thinkers are brief and primarily in the service of the bigger picture, but some thinkers get fairly extensive discussion (Marx, Burke), and a reader could walk away from the text with a fairly good understanding of their main lines of argument. The text does an excellent job of providing historical context and showing the deep and often complex roots of contemporary ideologies. Although the text emphasizes the modern roots of ideology, it has brief but substantial discussions of thinkers throughout the political theory tradition. Finally, there is an interesting contrast in tone between Baradat and Ball et al. Baradat's tone suggests that while ideologies are inevitable and very important, they are also in some way distasteful, that they are oversimplified marching orders for the deracinated and confused masses, bastardizations of political philosophies. In contrast, Ball et al. seem to view ideologies as not merely inevitable but as genuinely helpful-they are translations of political philosophies into practical terms, and help us to organize and categorize our extremely complex world into manageable terms.

\section{Hoffman and Graham, Introduction to Political Theory (3rd edition)}

In terms of the split between a focus on ideologies and a focus on political theory/philosophy, Hoffman and Graham represents a compromise. The book begins with a discussion 
of concepts central to classical political philosophy (the state, freedom, justice), moves on to a discussion of the (modern) ideologies that were based on those classical ideas (liberalism, conservatism, anarchism, etc.), then looks at more contemporary ideologies (feminism, ecologism, fundamentalism), and finally concludes by looking at some of the contemporary ideas that underlie those new ideologies (human rights, difference, and so on). This means that they discuss thinkers and arguments from the entire time span of the political theory tradition, and that they include non-Western ideas and thinkers in those discussions. Because the book is organized by ideas rather than thinkers, their discussions of individual political theorists are generally brief and in the service of the big picture, but a few thinkers get extensive treatment (Mill), and a few crop up in several chapters, such that a student who read the whole book would have a good understanding of imperfect arguments nonetheless inspiring and insightful. This isn't a serious failing, and they are certainly careful to present all the arguments they consider in accurate and sympathetic terms, but as a matter of personal taste about how I like to approach teaching political theory, I think I would be unlikely to use their book because of this focus on evaluation over appreciation.

\section{MONOGRAPHS-AS-TEXTBOOKS}

\section{Smith, Political Philosophy}

The three True Textbooks discussed previously are all organized into chapters by ideas or concepts. Steven Smith's book represents a transition between that approach and Klosko's approach of organizing chapters by thinker (with some thinkers meriting multiple chapters). Thus Smith's chapters are nearly all about individual thinkers or texts (Antigone, the Bible),

\section{Having taken a number of classes in political theory from the political science depart- ment, and a number in political philosophy from the philosophy department, and having read many of the same texts in those various courses, he neatly summed up what seemed to him the essence of the difference between the two approaches: political theory is about why everyone's right, and political philosophy is about why everyone's wrong.}

their ideas (Nozick, and especially Rawls). The chapters are thorough, well-balanced discussions of the topics, with extensive discussion both of major works in political theory and of recent scholarship.

My only quibble with this book is such a matter of taste that I hesitate even to mention it, except that I suspect it points to a matter of disciplinary focus. A few years ago I had an excellent student who was a political science / philosophy double major. Having taken a number of classes in political theory from the political science department, and a number in political philosophy from the philosophy department, and having read many of the same texts in those various courses, he neatly summed up what seemed to him the essence of the difference between the two approaches: political theory is about why everyone's right, and political philosophy is about why everyone's wrong. In other words, political theory courses tended to focus on showing the students why the various arguments were persuasive, on the ways in which they captured something that seems true and useful, while the political philosophy courses tended to focus on whether the arguments were valid and supported with adequate evidence. Thus the political theory courses tended to appreciate theories while forgiving the flaws in their arguments, while the political philosophy courses tended to build better arguments but at the cost of overlooking what had made the theories compelling to so many generations of thinkers. With that admittedly oversimplified distinction in mind, my quibble with Hoffman and Graham is that their emphasis is on assessing the validity of the arguments put forward about various concepts (liberty, equality, etc.), and that that focus leaves them less room to emphasize what makes the various but they use their detailed, in-depth readings of those thinkers and texts to make broader points about key issues and concepts in political thought (such as chapter eleven: "Tocqueville and the Dilemmas of Democracy").

Although the chapters discuss individual thinkers and texts in some depth, they are always doing so to make a larger point, and thus they don't exhaust what an instructor might want to draw from a text in class. That seems to me like a very good thing, since one thing that would worry me about using a textbook is the fear that it would say everything that I thought needed to be said about a particular text, leaving me nothing to do in class but echo it and guide discussion. Because the text focuses on thinkers rather than themes, there is an inevitable limit to how broad and complete its coverage can be. Smith's book focuses on canonical texts and thinkers (Sophocles, Plato, Aristotle, the Bible, Machiavelli, Hobbes, Locke, Rousseau, Tocqueville), though the discussions of broader themes allows Smith to touch on more recent political theory here and there. But if you want a textbook to include substantial discussions of nineteenth and twentieth century thinkers and intellectual movements, or non-Western political theory, this is not the book for you.

Stylistically, the book is clearly written, in an accessible but scholarly tone. Smith is not afraid to make judgments and stake claims. For example, in discussing the interpretation that we can find in Antigone's defiance of Creon an early version of the conflict between the inner conscience of the individual and the pressure for conformity from the broader society, Smith states flatly: "This view of Antigone is false" (Smith 2012, 16). In contrast to the occasional summary judgments that crop up in Baradat, Smith is careful to state 
his reasons, which leaves open the possibility of principled disagreement. The argument often brings in a variety of sources and ideas from many places, which was both helpful and an impressive display of erudition.

\section{Klosko, History of Political Theory (2nd edition; in two volumes)}

Klosko's two-volume text is squarely in the mold of an excellent scholarly examination of canonical thinkers from Socrates to Marx, with a few chapters providing essential background (for example, on the Greek polis) or discussing important movements that cannot easily be represented by one thinker (the Reformation). The organizing principle is that the text is meant to help students trace the origins and development of the liberal tradition, meaning roughly political theory concerned with how free, equal, and independent individuals cooperate together through government.

The various chapters provide thorough, detailed readings of the political writings and ideas of the various thinkers. If I were using this text, I doubt that I would assign long primary readings from the covered texts, because there would be little that I would want to add. The discussions bring in both the major political works and many minor or ostensibly nonpolitical works, and the result is an impressive, fairly conventional reading of the canon, informed by major scholarship about it. Klosko's focus on the individual thinkers leaves him even less room to touch on twentieth-century thinkers and movements than Smith had, and the result is that there is little to no discussion of more recent political theory or the various critical movements that have challenged the makeup of the canon. For example, while fascism merits two citations in the index, feminism does not appear at all. Rawls gets two mentions, but Nietzsche none. This helps to clarify some of the choices to be made when choosing a textbook. If what you want is an excellent, detailed discussion of the traditional canon, Klosko is an excellent choice. If you want something other than that, Klosko will not fill the bill.

\section{SUPPLEMENTARY MONOGRAPHS}

\section{Wolff, An Introduction to Political Philosophy and Milller, Political Philosophy: A Very Short Introduction}

Both the Wolff and Miller texts return to chapters based on concepts rather than individual thinkers, which seems inevitable in very brief introductory texts such as these. Both are written in a conversational tone that would be accessible to a wide audience, though both are serious and careful. There is nothing "dumbed down" about these texts (or any of the books under review, for that matter). Both texts discuss concepts, texts, and thinkers from the traditional canon as well as contemporary thinkers (like Rawls) and critical movements (like feminism); Miller is a bit broader, but briefer and less in-depth. To my eyes, the main difference between the two books is a subtle issue of intent. Miller seems most concerned with demonstrating to readers why the various concerns of political theory are important, and then providing a brief summary of the range of debate about the various issues. Wolff addresses the importance issue more quickly, and then turns to laying out the range of debate and asking which of the common positions are most defensible. In common with the other books under review that are organized by concepts, the discussions of individual thinkers and texts are brief and illustrative, but a few get sustained treatment (Rawls in the case of Wolff; Mill and Hobbes in the case of Miller).

\section{CONCLUSION}

As I suggested above, the decisions both of whether to use a textbook, and if so, which one to use, depend on how one wants to balance the various trade-offs involved with teaching political theory. Those trade-offs include the five I defined aboveBreadth vs. Depth, Text vs. Context, Debate vs. Meta-debate, Macro vs. Micro, and Raw vs. Cooked-as well as a few that have emerged in the course of discussing the books under review. Those new trade-offs concern the role that a textbook plays in a course (True Textbooks vs. Monographs-as-Textbooks vs. Supplementary Monographs), the analytical focus of the course (Ideology vs. Political Theory/Philosophy), the goal of the course (Appreciation vs. Evaluation), and finally the scope of the course's coverage (Canonical vs. Trans-canonical). Any of the books under review would be a fine choice, depending on what it is you want to accomplish and which flavor of political theory you prefer.

\section{NOTES}

1. I did exclude one textbook available through Amazon for $\$ 2,000$, as well as two that were available new from Amazon but not listed as in print on their publisher's web site.

2. This methodology has some obvious drawbacks, in that recently published titles and new editions may rank lower than they should due to being on the market for a short time, as may texts that exist in many variations (hard cover, soft cover, e-book, and so on) and therefore have their sales numbers split up. And of course there's the possibility that, despite diligent efforts, I may simply have overlooked some relevant texts. With apologies to any authors whose texts were inadvertently slighted, these were the best methods that were reasonably available, and I ask readers to bear these caveats in mind.

3. The texts are explicitly designed for a two-semester introductory sequence of courses.

\section{REFERENCES}

Ball, Terence, Richard Dagger, and Daniel O'Neill. 2013. Political Ideologies and the Democratic Ideal. Ninth ed. London and New York: Routledge.

Hajjar, Sami G. and Steven Brzezinski. 1978. "Teaching Normative Political Theory: A Nationwide Faculty Survey.” Teaching Political Science 5 (3): 295-306.

Moore, Matthew J. 2011. "How (and What) Political Theorists Teach: Results of a National Survey." Journal of Political Science Education 7 (1): 95-128. doi: 10.108o/15512169.2011.539921.

Smith, Steven B. 2012. Political Philosophy, Open Yale Courses. New Haven and London: Yale University Press. 